\title{
Cell Death in Plant Immunity
}

\author{
Eugenia Pitsilii, ${ }^{1}$ Ujjal J. Phukan, ${ }^{1}$ and Nuria S. Coll \\ Centre for Research in Agricultural Genomics (CRAG), CSIC-IRTA-UAB-UB, Bellaterra 08193, Barcelona, Spain \\ Correspondence: nuria.sanchez-coll@cragenomica.es
}

Pathogen recognition by the plant immune system leads to defense responses that are often accompanied by a form of regulated cell death known as the hypersensitive response (HR). HR shares some features with regulated necrosis observed in animals. Genetically, HR can be uncoupled from local defense responses at the site of infection and its role in immunity may be to activate systemic responses in distal parts of the organism. Recent advances in the field reveal conserved cell death-specific signaling modules that are assembled by immune receptors in response to pathogen-derived effectors. The structural elucidation of the plant resistosome-an inflammasome-like structure that may attach to the plasma membrane on activation - opens the possibility that HR cell death is mediated by the formation of pores at the plasma membrane. Necrotrophic pathogens that feed on dead tissue have evolved strategies to trigger the HR cell death pathway as a survival strategy. Ectopic activation of immunomodulators during autoimmune reactions can also promote HR cell death. In this perspective, we discuss the role and regulation of HR in these different contexts.

$\mathrm{T}_{\mathrm{p}}^{\mathrm{o}}$ detect potential invaders and respond appropriately, plants have evolved a complex and fine-tuned immune system. Current models have both extracellular and intracellular plant immune receptors initiating signaling cascades in response to invasion (Cook et al. 2015). In turn, potential invaders have developed diverse virulence strategies to evade or subvert plant immunity.

A form of regulated cell death known as the hypersensitive response (HR) is a frequent consequence of pathogen recognition by the plant immune system. The term hypersensitivity stems from the abnormally rapid death of plant cells encountering biotrophic pathogens, which rely on plant living tissue for their survival (Stakman 1915). HR can be manipulated genet- ically and is under tight control to avoid runaway cell death beyond the site of infection. HR cell death resembles forms of regulated necrosis in mammals, such as necroptosis and pyroptosis, but it also features some apoptosis-like traits (Vanden et al. 2014; Dickman et al. 2017; Galluzzi et al. 2018; Salguero-Linares and Coll 2019). Cell contents leaked during HR cell death may alert other cells to a potential invasion.

HR cell death has been studied mostly in the context of plant defense against biotrophic pathogens or hemibiotrophic pathogens, the latter having an initial biotrophic phase followed by a necrotrophic phase. However, necrotrophic pathogens that feed on dead or dying tissue can hijack HR cell death for their own benefit. Here, we provide a perspective on HR cell death

\footnotetext{
${ }^{1}$ These authors contributed equally to this work.

Editors: Kim Newton, James M. Murphy, and Edward A. Miao

Additional Perspectives on Cell Survival and Cell Death available at www.cshperspectives.org

Copyright $\odot 2020$ Cold Spring Harbor Laboratory Press; all rights reserved; doi: 10.1101/cshperspect.a036483

Cite this article as Cold Spring Harb Perspect Biol 2020;12:a036483
} 
E. Pitsili et al.

signaling based on recent advances in the molecular interactions between plant and pathogens, plus we discuss autoimmunity as a trigger of HR cell death in the context of certain mutations or during hybrid necrosis.

\section{IMMUNE HR CELL DEATH AS A CONSEQUENCE OF PATHOGEN RECOGNITION}

The plant immune system is constantly evolving to detect invasive microbes or their effects on the plant. Initially, plasma membrane patternrecognition receptors (PRRs) were thought to recognize conserved microbe-associated molecular patterns, whereas cytoplasmic NLRs (nucleotide-binding domain leucine-rich repeat (LRR)-containing gene family) sensed pathogenic virulence factors or their perturbations to the cell (Jones and Dangl 2006). However, as our knowledge of plant immunity has advanced, it has become evident that PRRs also respond to virulence effectors. NLRs may also "guard" conserved molecules that act as rheostats in plant immune responses (Cook et al. 2015).

In terms of domain architecture, plant NLRs resemble animal NLRs, with a variable aminoterminal domain, a central nucleotide-binding domain, and a highly polymorphic carboxy-terminal leucine-rich domain (Fig. 1). Plant NLRs are classified according to their amino-terminal domains as Toll/interleukin-1 receptor (TIR) domain NLRs (also known as TNLs) or coiledcoil (CC) domain NLRs (or CNLs) (Cui et al. 2014; Zhang et al. 2017). NLRs recognize effector molecules deployed by pathogens, either directly or indirectly, and then initiate signaling cascades that culminate in the expression of genes mediating host defense (Cui et al. 2014). An emerging model in plant immunity is that NLRs work in functionally specialized pairs or even more complex networks, with sensor NLRs perceiving pathogen effectors and helper NLRs initiating downstream signaling (Bonardi et al. 2012; Wu et al. 2017).

Recognition of adapted biotrophic or hemibiotrophic pathogens by the plant immune system often leads to HR cell death. Thus, HR cell death is frequently described as an immune

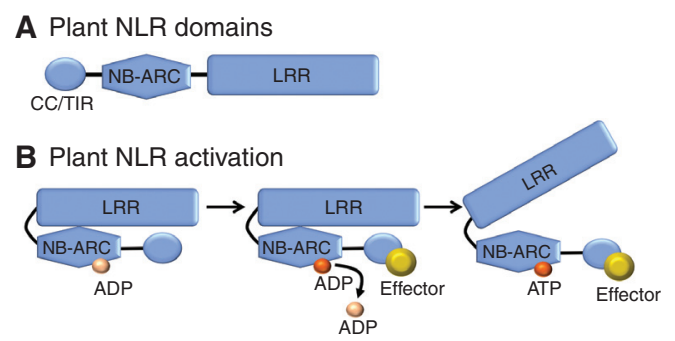

Figure 1. Plant NLRs (nucleotide-binding domain leucine-rich repeat (LRR)-containing gene family). (A) Schematic representation of a plant NLR protein. The amino-terminal region usually contains a Toll/ interleukin-1 receptor (TIR) homology or a coiledcoil (CC) domain. The central region is composed of a nucleotide-binding APAF-1, $\mathrm{R}$ proteins, and CED-4 (NB-ARC) domain. The carboxy-terminal region contains an LRR domain. (B) NLR activation. In the inactive, closed state, $\mathrm{ADP}$ is bound to the NBARC domain. Direct or indirect effector recognition, results in ADP release and ATP binding. This results in a conformational change that renders an open, active NLR.

strategy to block pathogen colonization. However, this is not always the case, because there are numerous examples of HR cell death and inhibition of pathogen growth being genetically uncoupled (Yu et al. 1998; Greenberg et al. 2000; Balagué et al. 2003; Jurkowski et al. 2004; Coll et al. 2010; Sheikh et al. 2014; Menna et al. 2015; Lapin et al. 2019). As shown in Figure 2, HR cell death at the site of infection is crucial to initiate systemic signals that activate immunity in distal parts of the plant and eventually lead to resistance. This phenomenon is known as systemic acquired resistance (SAR) (Fu and Dong 2013; Shine et al. 2019).

Although we are far from an integrated view of HR signaling, research in the last 30 years has substantially increased our understanding of the molecular mechanisms controlling HR. Downstream from NLR activation, HR involves a series of events that include calcium influxes, oxidative bursts originating in different cellular compartments, hormone signaling, mitogenactivated protein kinases, and transcriptional reprogramming (Adachi and Tsuda 2019). Most of these elements are shared between PRR and NLR signaling, and HR cell death has often been 


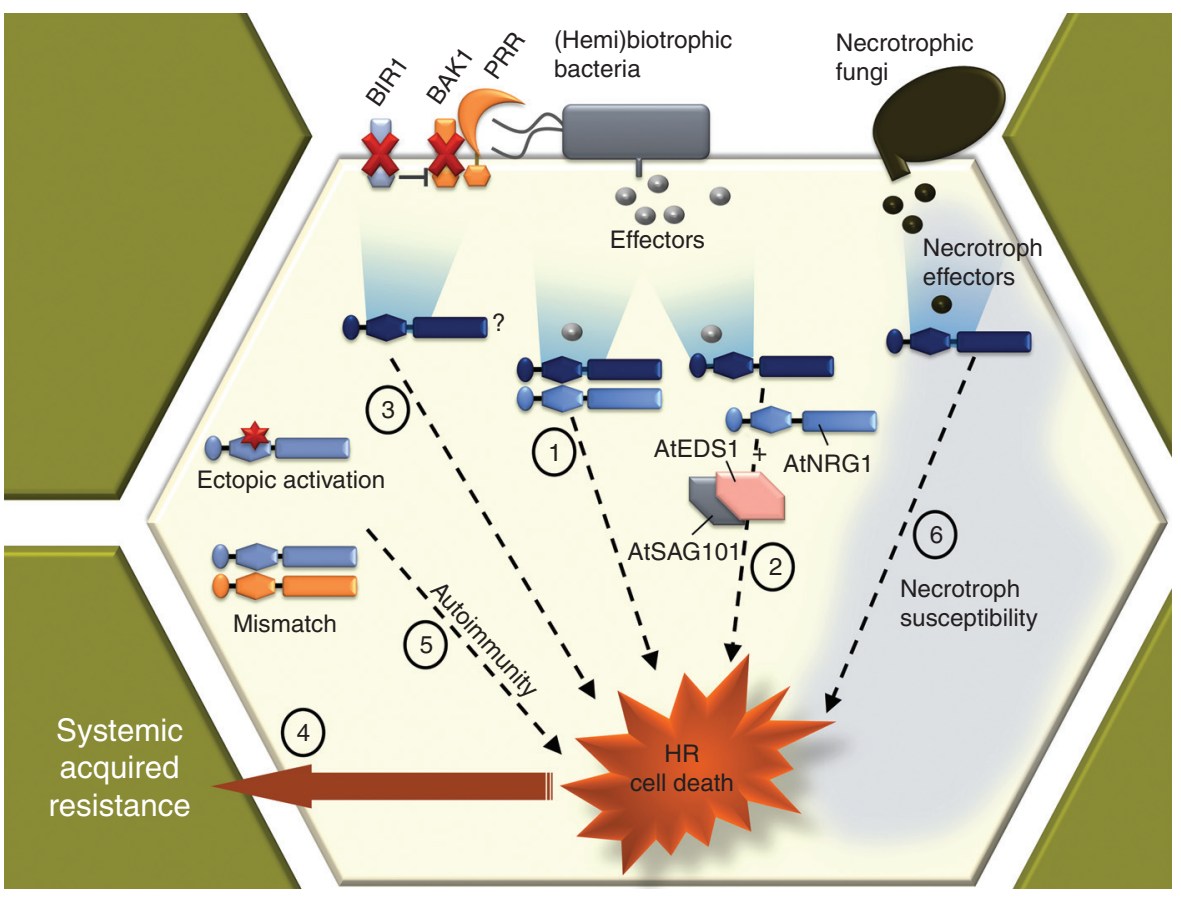

Figure 2. Pathways leading to hypersensitive response (HR) cell death in plant immunity. (1) HR can be triggered on recognition of a biotrophic or hemibiotrophic pathogen via direct or indirect effector recognition by NLR (nucleotide-binding domain leucine-rich repeat-containing gene family) immune receptors, often operating in pairs (sensor NLR + helper NLR). (2) Cell death-specific modules have been identified, which translate the signal generated by effector perception via Toll/interleukin-1 receptor domain NLR (TIR-NLR) activation, into HR cell death. (3) Pattern-recognition receptors (PRRs) signaling at the plasma membrane may be monitored by NLRs, with PRR signaling disturbance leading to HR cell death. (4) HR cell death can be genetically uncoupled from local defense responses, but may have a role in activating systemic resistance responses. (5) HR can occur as a result of autoimmune reactions, owing to the ectopic activation of NLRs or other defense signaling modulators or an NLR mismatch. (6) Necrotrophic fungi can cause disease by hijacking the host HR cell death. A common strategy is activation of NLR receptors by toxins secreted by the fungi into the plant cytoplasm.

regarded as a consequence of surpassing certain signaling thresholds, rather than as a highly regulated phenomenon. However, this view is challenged by recent findings that shed light on HR-specific signaling.

\section{Cell Death Signaling Hubs and the Resistosome}

Recent work indicates the importance of signaling hubs downstream from NLR activation, which may partition cell death and immune responses (Wu et al. 2016, 2017; Qi et al. 2018; Castel et al. 2019; Lapin et al. 2019). The lipase-like protein ENHANCED DISEASE
SUSCEPTIBILITY1 (AtEDS1) mediates all resistance outputs downstream from activated TNLs (Wiermer et al. 2005). As shown in Figure 2, AtEDS1 interacts with SENESCENCE-ASSOCIATED GENE101 (AtSAG101), and this heterodimer functions together with the helper CNL family member N Requirement Gene 1 (AtNRG1) to form a cell death signaling module in Arabidopsis thaliana that can be transferred to unrelated plant species. In parallel, transcriptional reprogramming to enhance the basal defense response is mediated by the interaction of EDS1 with PHYTOALEXIN-DEFICIENT 4 (AtPAD4) and a different helper CNL, ACCELERATED DISEASE RESISTANCE 1 (AtADR1) (Lapin et 
E. Pitsili et al.

al. 2019). Helper NLRs have a high degree of redundancy in plant genomes, which may allow functional diversification and expansion of their corresponding sensor NLRs. For example, functionally redundant members of the helper NLR family NRC (NLR required for cell death) may contribute to immunity against different types of pathogens via their interactions with particular sensor NLRs (Wu et al. 2017). Studying interactions and outputs between the components of all these signaling modules is complex because they vary between plant species and according to the pathogen under study. In fact, we still do not know how the signals emanating from these modules execute cell death.

Clues were provided earlier this year by the reconstitution of an NLR supramolecular struc- ture termed the resistosome (Wang et al. 2019a, b). The resistosome has been hypothesized to directly induce HR by forming pores in the plasma membrane, an exciting idea that awaits testing. This immune complex, with stunning structural and mechanistic similarities to mammalian inflammasomes, is composed of the NLR HOPZ-ACTIVATED RESISTANCE 1 (ZAR1) and two receptor-like cytoplasmic kinases (RLCKs) (Fig. 3). In its resting state, ZAR1 is bound to ADP and the RLCK RESISTANCE-RELATED KINASE 1 (RKS1). RKS1 (RLCK XII) is a pseudokinase that interacts with the LRR domain of ZAR1 (Roux et al. 2014). The bacterial pathogen Xanthomonas campestris uses a type III secretion system to deliver the bacterial effector AvrAC into the

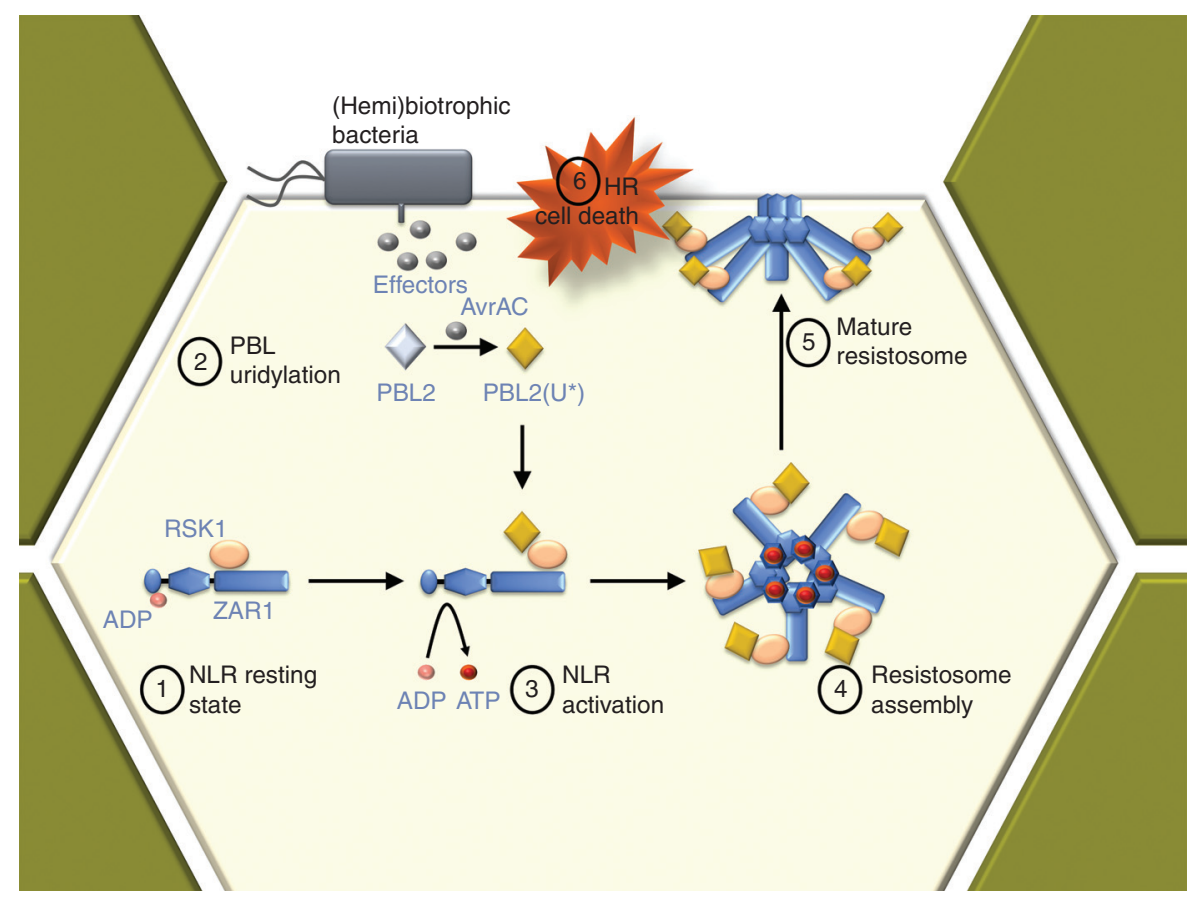

Figure 3. Mechanism of resistosome activation. (1) In its resting state, the NLR HOPZ-ACTIVATED RESISTANCE 1 (ZAR1) is bound to ADP and the RLCK RESISTANCE-RELATED KINASE 1 (RKS1). (2) Xanthomonas campestris secretes the effector AvrAC into the host plant cells, which uridylates the RLCK PBS1-LIKE PROTEIN 2 (PBL2). (3) Uridylated PBL2 binds to RKS1, causing conformational changes to the ZAR1-RKS1 dimer that release ADP and prime the complex for activation. (4) Subsequent ATP binding results in formation of the resistosome via pentamerization of the ZAR1-RKS1-PBL2 complex. (5) Conformational changes expose a funnel-like structure essential for accumulation of the complex in the plasma membrane, bacterial resistance, and (6) cell death, which has been hypothesized to be mediated by pore formation at the plasma membrane on insertion of the resistosome. 
plant cytoplasm, where it uridylates a decoy RLCK, PBS1-LIKE PROTEIN 2 (PBL2) (Wang et al. 2015a). Unlike RKS1, PBL2 is an active kinase, but its catalytic activity appears dispensable for immune defense. Instead, modified PBL2 (RLCK VII) binds to RKS1 in the ZAR1RKS1 dimer, causing conformational changes that release $\mathrm{ADP}$ and prime the complex for activation. Subsequent ATP binding drives formation of the resistosome via pentamerization of the ZAR1-RKS1-PBL2 complex. Intriguingly, formation of the resistosome exposes a funnel-like structure that is essential both for resistance to bacteria and for accumulation of the complex in the plasma membrane (Fig. 3). This "death-fold switch" may act in an analogous manner to the membrane pores and ion channels formed by mixed lineage kinase domain-like (MLKL) or gasdermins in mammals, or during NLR activation in fungi, potentially suggesting a common evolutionary origin of NLRs from plants and animals (Adachi et al. 2019).

Rather than being the direct cause of cell death, these potential pores could mediate specific ion influxes that activate HR-specific downstream signaling, such as activation of cell death executioner proteases (Dangl and Jones 2019; Feng and Tang 2019). For example, the metacaspase AtMC4 is rapidly activated by calcium that enters the cell on loss of membrane integrity (Huang et al. 2018; Hander et al. 2019). Activation of AtMC4 results in cleavage of the precursor protein PROPEP1, which releases the danger peptide Pep1 to trigger wound-induced defense signaling. This program shares many components with pathogen-induced defense responses. Whether AtMC4 or other proteases are activated by resistosome pores will certainly be worth analyzing in the coming years.

\section{PRR Perturbation as an HR Trigger}

Plasma membrane signaling may have a very important role in HR signaling. When PRRs in the plasma membrane sense certain microbial molecular patterns, they team up with coreceptors in specific nanodomains that initiate signaling cascades (Bücherl et al. 2017). For example, knocking out or overexpressing AtBAK1 (BRAS-
SINOSTEROID INSENSITIVE1-ASSOCIATED RECEPTOR KINASE1), a coreceptor of several different PRRs, leads to a potent HR cell death response and enhanced resistance to hemibiotrophic pathogens (Kemmerling et al. 2007; Domínguez-Ferreras et al. 2015). The fact that overexpression or elimination of a required element for PRR signaling leads to the same HR phenotype may indicate that perturbation or damage to components of PRR signaling is also monitored (Tang and Zhou 2016). This strategy would allow plant cells to defend against pathogen-mediated inhibition of PRR pathways. Accordingly, inactivation of another PRR regulator, the plasma membrane receptor-like kinase AtBIR1, also results in HR cell death (Liu et al. 2016a).

\section{Proteolytic Pathways Associated with HR}

Signaling downstream from NLRs may impact finely tuned proteolytic pathways, including (selective?) autophagy and the concerted action of several proteases (Hofius et al. 2017; SalgueroLinares and Coll 2019). Various proteases in the cytoplasm (metacaspases, phytaspase, or the proteasome subunit PBA1), in the vacuole (vacuolar processing enzyme [VPE]), and those secreted to the extracellular space (cathepsin B, saspase, Rcr3, Pip1) have been shown to be essential for HR cell death (Salguero-Linares and Coll 2019). In fact, they need to be tightly controlled to limit cell death beyond the HR site. Hence, the multiple levels of negative regulation exerted on, for example, the HR cell death protease METACASPASE1 (AtMC1) by the protease inhibitor SERPIN1, the scaffold protein LESION SIMULATING DISEASE 1 (AtLSD1), and the metacaspase AtMC2 (Coll et al. 2010; Lema Asqui et al. 2018). Moreover, AtMC1 has been shown to act additively to autophagy in controlling HR cell death (Coll et al. 2014). Although it is clear that autophagy promotes HR cell death, the mechanism and precise function (trigger or executioner?) remain unknown (Hofius et al. 2009; Coll et al. 2014; Munch et al. 2014). Intriguingly, to date, no canonical proteolytic cascade has ever been characterized in plants (Paulus and Van der Hoorn 2019). The 
E. Pitsili et al.

coming years will hopefully provide a deeper insight into this HR-related proteolysis as the study of plant autophagy in plant-pathogen interactions has witnessed a tremendous expansion in the last few years (Avin-Wittenberg et al. 2018) and plant proteostasis is becoming a fully-fledged field of study.

\section{Local versus Peripheral Regulation of HR}

It will be important to pay closer attention to the spatiotemporal magnitude of HR in the coming years. This aspect has often been disregarded, with many studies of infected tissue not discriminating between HR versus non-HR cells. There are several examples of differential or antagonistic signaling between the cells undergoing HR and those in the surrounding area. This is true for the metacaspases AtMC1 and AtMC2, which antagonistically regulate $\mathrm{HR}$ cell death, and are expressed at the site of HR (AtMC1) or in the cells surrounding the $\mathrm{HR}$ zone (AtMC2) (Coll et al. 2010). The transcription factor AtMYB30, which mediates HR cell death and immune responses, has also been shown to be differentially regulated within HR and nonHR zones (Raffaele and Rivas 2013). Finally, signaling pathways downstream from the defense hormones salicylic acid and jasmonic acid are activated in spatially different domains during HR, with salicylic acid in the cell death zone and jasmonic acid in the surrounding area (Betsuyaku et al. 2018). Thus, it will be extremely important to define spatiotemporal markers of HR cell death, so that in the future we can time and characterize the events leading to HR cell death. These markers will help discriminate cells undergoing HR cell death from the surrounding tissue, which needs to activate protective mechanisms to survive, while integrating and transmitting danger/immune signals from dying cells to protect the organism against invasion.

\section{MANIPULATION OF IMMUNE HR CELL DEATH BY NECROTROPHS AS A VIRULENCE STRATEGY}

Necrotrophic pathogens have been regarded as generalists, but it is now evident that their inter- action with the plant host is complex and highly regulated. Necrotrophs secrete toxins that kill plant cells and leave remnants from which the pathogen can feed. These pathogens have evolved very sophisticated strategies to trigger cell death. The most common strategy seems to be hijacking HR cell death pathways by subverting components of the plant immune system.

Secreted toxins, also known as necrotroph effectors (NEs), are recognized by the so-called NE-sensitive genes and trigger HR cell death (Fig. 2). Several NE-sensitive genes possess classical nucleotide-binding and LRR domains, and they often have roles in defense against biotrophic or hemibiotrophic pathogens (Lorang et al. 2007, 2012; Faris et al. 2010). Thus, NE genes appear to be a double-edged sword, being effective at eliciting an $\mathrm{HR}$ response to contain biotrophic pathogens, but able to be hijacked by NEs to confer plant susceptibility. A classic example is LOV1 (LONG VEGETATIVE PHASE1), an NLR from $A$. thaliana that confers susceptibility to Cochliobolus victoriae (Lorang et al. 2007). This necrotrophic fungus secretes the effector victorin, which activates LOV1 and triggers a resistance-like response that culminates in HR cell death and proliferation of the pathogen (Lorang et al. 2012).

The intricate mechanisms regulating necrotroph-host interactions have also been showcased by the study of Sclerotinia sclerotiorum. This necrotrophic fungus triggers HR by secreting oxalic acid into plant cells (Kim et al. 2008). During the initial phases of the infection, oxalic acid reduces levels of reactive oxygen species and creates a reducing environment that favors pathogen proliferation. At the same time, host defenses are dampened and the infection progresses unnoticed. At later stages, and once the infection is well established, oxalic acid triggers an increase in reactive oxygen species that causes cell death (Williams et al. 2011). Oxalic acid has also been shown to inhibit autophagy-mediated cell death, which could provide an additional mechanism to camouflage infection and prevent activation of defense responses (Kabbage et al. 2013).

New NEs and their plant susceptibility targets are emerging from the interaction between 
wheat and the necrotrophic fungus Parastagonospora nodorum. For example, the effector ToxA is recognized indirectly by the NLR Tsn 1 from wheat, which results in HR cell death and disease (Faris et al. 2010). Another P. nodorum effector, Tox1, remains in the extracellular space and is proposed to have a dual role in infection. It binds to chitin in the fungal cell wall to protect it from degradation by host chitinases, while also inducing an HR-like response via its recognition by Snn1, a wall-associated receptor kinase (Liu et al. 2016b; Shi et al. 2016). Adding to the complexity, the susceptibility triggered by an NE can vary depending on the genetic backgrounds of the host and pathogen (Peters Haugrud et al. 2019). The identification of new susceptibility gene candidates in the host holds great potential for the generation of plants that are more resistant to necrotrophic fungi, which are a serious threat to agriculture. Understanding precisely how NE genes interact with their corresponding plant susceptibility genes may allow engineering of new plant protein targets that evade the effectors without compromising plant fitness and yield.

\section{HR CELL DEATH AS A CONSEQUENCE OF AUTOIMMUNITY}

HR cell death can also be observed in plants in the absence of pathogens. This autoimmunity leads to ectopic defense activation and spontaneous cell death in the form of macroscopic disease-like lesions (Chakraborty et al. 2018). Plant autoimmunity can be triggered by gain or lossof-function of plant immune modulators (NLRs and non-NLRs), autophagy, and impaired metabolic processes. In the 1990s, lesion mimic mutants (LMMs), which are plants with spontaneous or mutagenesis-induced mutations showing HR-like cell death in the absence of pathogen, emerged as a promising tool to characterize $\mathrm{HR}$ cell death. Characterization of these genes, mostly in A. thaliana and rice, has highlighted the importance of several cellular compartments and pathways in HR signaling, including chloroplasts and light energy, sphingolipids and fatty acids, ROS and ion fluxes, autophagy, and plasma membrane signal perception (Brugge- man et al. 2015). Forward genetic screens targeting LMM revertants have identified additional components of defense signaling pathways, which has led to the idea that LMM phenotypes can be caused by loss of a pathogen effector target that is guarded by an NLR. Subsequent activation of the NLR promotes HR cell death (Rodriguez et al. 2016; Lolle et al. 2017).

The study of autoactive NLR alleles has also been informative. For example, the snc1-1 (Suppressor of NPR1, Constitutive 1) mutant is a constitutively active variant of the SNC1 TLR that causes autoimmunity and HR cell death (Li et al. 2001). Autoactive SNC1 has been shown to activate immune responses in the nucleus, where it represses small RNAs involved in NLR silencing (Cai et al. 2018), and it associates with a transcriptional corepressor that blocks expression of negative regulators of immunity (Zhu et al. 2010). To ensure appropriate activation of SNC1-dependent immunity, multiple repression mechanisms directed toward this protein have been shown at the transcriptional level as well as posttranscriptionally (Zhu et al. 2010; Cheng et al. 2011; Huang et al. 2014; Johnson et al. 2015, 2017; Dong et al. 2016; Gou et al. 2017; Wang et al. 2017a,b, 2019c; Cai et al. 2018; Zhang et al. 2018; Niu et al. 2019). The Rp1-D21 gene in maize, which derives from an intergenic recombination event between two NLR genes, $R p 1-D$ and $R p 1-d p 2$, provides another example of NLR autoactivation resulting in HR cell death (Chintamanani et al. 2010). Intramolecular interactions drive activation of Rp1-D21, although HR cell death requires light and temperatures below a certain threshold (Negeri et al. 2013; Wang et al. 2015b). Recently, it was shown that two key enzymes of the lignin biosynthetic pathway form complexes with this hybrid NLR and modulate its activity (Wang and Balint-Kurti 2016).

Autoimmunity leading to ectopic HR cell death can also be a consequence of hybrid necrosis, which is a common type of incompatibility found in the progeny of many crosses within and between species (Fig. 2). In contrast to hybrid vigor, hybrid incompatibility challenges plant fitness and can result from mismatched NLRs (Chen et al. 2016; Vaid and Laitinen 
E. Pitsili et al.

2019). Indeed, genes causing hybrid necrosis are often associated with plant defense responses (Alcazar et al. 2009). Allelic interactions at the ACD6 (ACCELERATED CELL DEATH 6) locus in A. thaliana lead to hybrid necrosis and the enhanced expression of defense genes (Świadek et al. 2017). In fact, ACD6 acts as a quantitative resistance gene that balances growth and pathogen resistance in natural populations of A. thaliana, and it has been shown that deleterious autoimmune ACD6 alleles are modulated by natural variants of SNC1 (Zhu et al. 2018).

The hybrid necrosis hot spots in the A. thaliana genome are often densely populated with NLRs. These immune receptor loci act as hypermodulated complexes that recombine between natural genetic variants and cause imbalanced NLR activity (Chae et al. 2014). The Bateson-Dobzhansky-Muller model explains pairwise heteromeric interactions between distinct unlinked NLR loci that lead to hybrid necrosis and enhanced defense (Phadnis and Malik 2014). On the one hand, the polymorphic nature (high levels of sequence divergence) of these immune loci gives an advantage during the host response to pathogen challenges, while on the other hand it positively correlates to hybrid necrosis impacting plant fitness. Different NLR pairs have been involved in the hybrid necrosis phenomena (Bomblies and Weigel 2007; Tran et al. 2017; Atanasov et al. 2018). Many questions regarding hybrid necrosis remain unanswered. How is the NLR-mediated defense response propagated without pathogen challenge? What is the role of environmental factors and genetic distance in hybrid necrosis induction? How can the deleterious fitness effects be mitigated during interspecific crossing while preserving the resistance trait? Our understanding of the mechanisms regulating HR cell death triggered by autoimmunity is still very limited. A deeper understanding of NLR activation and signal transduction will help us integrate and advance the current knowledge.

\section{CONCLUDING REMARKS}

In plant immunity, HR cell death is often used to score resistance to pathogens. However, the mechanisms regulating this complex phenomenon are far from understood. The intricate interplay between sensor and helper immune receptors is starting to emerge, and will help shed light on how cell death is triggered and executed on pathogen perception. Cell deathspecific modules are being unveiled as integrators of signals emanating from activation of diverse sensor NLRs. HR cell death is an important part of the immune response to protect distal parts of the plant against future invasions.

The plant resistosome has been described as an inflammasome-like supramolecular structure that assembles on recognition of pathogenic effectors to initiate defense responses. The activated resistosome features a funnel-like structure that is required for insertion of the complex into the plasma membrane and HR cell death. It has been speculated that this structure creates pores in the membrane, which could mediate ion fluxes that activate cell death enzymes. Perturbation of the plasma membrane or its signaling components-including PRRs-may also be monitored by NLRs that can trigger HR cell death.

In addition to immunity against biotrophic and hemibiotrophic pathogens, HR cell death can also mediate susceptibility to necrotrophic pathogens. There are several examples of necrotrophic fungi secreting toxins (also known as NEs) that directly or indirectly activate specific NLRs and cause HR cell death. These NLRs were probably selected in the course of interactions between a plant and biotrophic pathogen, and then hijacked by a necrotrophic fungus for its own benefit. This is an emerging area of research with great potential, because susceptibility genes can serve as targets for genome-editing technologies aimed at increasing resistance against fungi in commercial cultivars.

The analysis of autoimmune phenotypes in plants is also providing a better understanding of the mechanisms regulating $\mathrm{HR}$ cell death. Autoactive or mismatched NLR alleles confer constitutive immunity and ectopic HR-like cell death phenotypes, highlighting the importance of a multilayered and finely tuned regulation of immune modulators to avoid deleterious fitness costs for the plant. The booming field of plant 
immunity will surely deepen our insight into the mechanisms regulating pathogen-triggered HR cell death, helping us understand to what extent it is programmed.

\section{ACKNOWLEDGMENTS}

We thank Mary-Paz González García, Marc Valls, and Jose Salguero-Linares for comments on the manuscript. We also thank Jane Parker and Hans Thordal-Christensen for inspiring discussions on the topic. We apologize to all authors whose work has been omitted because of space limitations. This work was supported by the Spanish Ministry of Economy and Competitiveness with Grant Nos. RyC 2014-16158 and AGL2016-78002-R and through the Severo Ochoa Programme for Centres of Excellence in R\&D (SEV-2015-0533). We also acknowledge financial support from the CERCA Programme/Generalitat de Catalunya.

\section{REFERENCES}

Adachi H, Tsuda K. 2019. Convergence of cell-surface and intracellular immune receptor signalling. New Phytol 221: 1676-1678. doi:10.1111/nph.15634

Adachi H, Kamoun S, Maqbool A. 2019. A resistosome-activated "death switch." Nat Plants 5: 457-458. doi:10 .1038/s41477-019-0425-9

Alcazar R, Garcia AV, Parker JE, Reymond M. 2009. Incremental steps toward incompatibility revealed by Arabidopsis epistatic interactions modulating salicylic acid pathway activation. Proc Natl Acad Sci 106: 334-339. doi:10.1073/pnas.0811734106

Atanasov KE, Liu C, Erban A, Kopka J, Parker JE, Alcázar R. 2018. NLR mutations suppressing immune hybrid incompatibility and their effects on disease resistance. Plant Physiol 177: 1152-1169. doi:10.1104/pp.18.00462

Avin-Wittenberg T, Baluška F, Bozhkov P V, Elander PH, Fernie AR, Galili G, Hassan A, Hofius D, Isono E, Le Bars R, et al. 2018. Autophagy-related approaches for improving nutrient use efficiency and crop yield protection. J Exp Bot 69: 1335-1353. doi:10.1093/jxb/ery069

Balagué C, Lin B, Alcon C, Flottes G, Malmström S, Köhler C, Neuhaus G, Pelletier G, Gaymard F, Roby D. 2003. HLM1, an essential signaling component in the hypersensitive response, is a member of the cyclic nucleotidegated channel ion channel family. Plant Cell 15: 365-379.

Betsuyaku S, Katou S, Takebayashi Y, Sakakibara H, Nomura N, Fukuda H. 2018. Salicylic acid and jasmonic acid pathways are activated in spatially different domains around the infection site during effector-triggered immunity in Arabidopsis thaliana. Plant Cell Physiol 59: 439. doi:10 .1093/pcp/pcy008
Bomblies K, Weigel D. 2007. Hybrid necrosis: autoimmunity as a potential gene-flow barrier in plant species. Nat Rev Genet 8: 382-393. doi:10.1038/nrg2082

Bonardi V, Cherkis K, Nishimura MT, Dangl JL. 2012. A new eye on NLR proteins: focused on clarity or diffused by complexity? Curr Opin Immunol 24: 41-50. doi:10.1016/j .coi.2011.12.006

Bruggeman Q, Raynaud C, Benhamed M, Delarue M. 2015. To die or not to die? Lessons from lesion mimic mutants. Front Plant Sci 6: 24. doi:10.3389/fpls.2015.00024

Bücherl CA, Jarsch IK, Schudoma C, Segonzac C, Mbengue M, Robatze S, MacLean D, Ott T, Zipfe C. 2017. Plant immune and growth receptors share common signalling components but localise to distinct plasma membrane nanodomains. eLife 6: e25114. doi:10.7554/eLife.25114

Cai Q, Liang C, Wang S, Hou Y, Gao L, Liu L, He W, Ma W, Mo B, Chen X. 2018. The disease resistance protein SNC1 represses the biogenesis of microRNAs and phased siRNAs. Nat Commun 9: 5080. doi:10.1038/s41467-01807516-Z

Castel B, Ngou PM, Cevik V, Redkar A, Kim DS, Yang Y, Ding P, Jones JDG. 2019. Diverse NLR immune receptors activate defence via the RPW8-NLR NRG1. New Phytol 222: 966-980. doi:10.1111/nph.15659

Chae E, Bomblies K, Kim ST, Karelina D, Zaidem M, Ossowski S, Martín-Pizarro C, Laitinen RAE, Rowan BA, Tenenboim H, et al. 2014. Species-wide genetic incompatibility analysis identifies immune genes as hot spots of deleterious epistasis. Cell 159: 1341-1351. doi:10.1016/j .cell.2014.10.049

Chakraborty J, Ghosh P, Das S. 2018. Autoimmunity in plants. Planta 248: 751-767. doi:10.1007/s00425-0182956-0

Chen C EZ, Lin HX. 2016. Evolution and molecular control of hybrid incompatibility in plants. Front Plant Sci 7: 110.

Cheng YT, Li Y, Huang S, Huang Y, Dong X, Zhang Y, Li X. 2011. Stability of plant immune-receptor resistance proteins is controlled by SKP1-CULLIN1-F-box (SCF)-mediated protein degradation. Proc Natl Acad Sci 108: 14694-14699. doi:10.1073/pnas.1105685108

Chintamanani S, Hulbert SH, Johal GS, Balint-Kurti PJ. 2010. Identification of a maize locus that modulates the hypersensitive defense response, using mutant-assisted gene identification and characterization. Genetics 184: 813-825. doi:10.1534/genetics.109.111880

Coll NS, Vercammen D, Smidler A, Clover C, Van Breusegem F, Dangl JL, Epple P. 2010. Arabidopsis type I metacaspases control cell death. Science 330: 1393-1397. doi:10.1126/science.1194980

Coll NS, Smidler A, Puigvert M, Popa C, Valls M, Dangl JL. 2014. The plant metacaspase AtMC1 in pathogen-triggered programmed cell death and aging: functional linkage with autophagy. Cell Death Differ 21: 1399-1408. doi:10.1038/cdd.2014.50

Cook DE, Mesarich CH, Thomma BPHJ. 2015. Understanding plant immunity as a surveillance system to detect invasion. Annu Rev Phytopathol 53: 541-563. doi:10 .1146/annurev-phyto-080614-120114

Cui H, Tsuda K, Parker JE. 2014. Effector-triggered immunity: from pathogen perception to robust defense. Annu 
E. Pitsili et al.

Rev Plant Biol 66: 487-511. doi:10.1146/annurev-ar plant-050213-040012

Dangl JL, Jones JDG. 2019. A pentangular plant inflammasome. Science 364: 31-32. doi:10.1126/science.aax0174

Dickman M, Williams B, Li Y, Figueiredo P, Wolpert T. 2017. Reassessing apoptosis in plants. Nat Plants 3: 773-779. doi:10.1038/s41477-017-0020-x

Domínguez-ferreras A, Kiss-papp M, Jehle AK, Felix G, Chinchilla D. 2015. An overdose of the Arabidopsis coreceptor BRASSINOSTEROID INSENSITIVE1ASSOCIATED RECEPTOR KINASE1 or its ectodomain causes autoimmunity in a SUPPRESSOR OF BIR1-1-dependent manner. Plant Physiol 168: 1106-1121.

Dong OX, Meteignier LV, Plourde MB, Ahmed B, Wang M, Jensen C, Jin H, Moffett P, Li X, Germain H. 2016. Arabidopsis TAF15b localizes to RNA processing bodies and contributes to snc1-mediated autoimmunity. Mol Plant Microbe Interact 29: 247-257. doi:10.1094/MPMI-11$15-0246-\mathrm{R}$

Faris JD, Zhang Z, Lu H, Lu S, Reddy L, Cloutier S, Fellers JP, Meinhardt SW, Rasmussen JB, Xu SS, et al. 2010. A unique wheat disease resistance-like gene governs effector-triggered susceptibility to necrotrophic pathogens. Proc Natl Acad Sci 107: 13544-13549. doi:10.1073/pnas .1004090107

Feng B, Tang D. 2019. Mechanism of plant immune activation and signaling: insight from the first solved plant resistosome structure. J Integr Plant Biol 61: 902-907 doi:10.1111/jipb.12814

Fu ZQ, Dong X. 2013. Systemic acquired resistance: turning local infection into global defense. Annu Rev Plant Biol 64: 839-863. doi:10.1146/annurev-arplant-042811-105 606

Galluzzi L, Vitale I, Aaronson SA, Abrams JM, Adam D, Agostinis P, Alnemri ES, Altucci L, Amelio I, Andrews DW, et al. 2018. Molecular mechanisms of cell death: recommendations of the nomenclature committee on cell death 2018. Cell Death Differ 25: 486-541. doi:10 .1038/s41418-017-0012-4

Gou M, Huang Q, Qian W, Zhang Z, Jia Z, Hua J. 2017. Sumoylation E3 ligase SIZ1 modulates plant immunity partly through the immune receptor gene $S N C 1$ in Arabidopsis. Mol Plant Microbe Interact 30: 334-342. doi:10 .1094/MPMI-02-17-0041-R

Greenberg JT, Silverman FP, Liang H. 2000. Uncoupling salicylic acid-dependent cell death and defense-related responses from disease resistance in the Arabidopsis mutant acd5. Genetics 156: 341-350.

Hander T, Fernández-fernández ÁD, Kumpf RP, Willems P Schatowitz H, Rombaut D, Staes A, Nolf J, Pottie R, Yao P et al. 2019. Damage on plants activates $\mathrm{Ca}^{2+}$-dependent metacaspases for release of immunomodulatory peptides. Science 363: eaar7486. doi:10.1126/science.aar7486

Hofius D, Schultz-Larsen T, Joensen J, Tsitsigiannis DI, Petersen NHT, Mattsson O, Jørgensen LB, Jones JDG, Mundy J, Petersen M. 2009. Autophagic components contribute to hypersensitive cell death in Arabidopsis. Cell 137: 773-783. doi:10.1016/j.cell.2009.02.036

Hofius D, Li L, Hafrén A, Coll NS. 2017. Autophagy as an emerging arena for plant-pathogen interactions. Curr Opin Plant Biol 38: 117-123. doi:10.1016/j.pbi.2017.04 .017
Huang Y, Minaker S, Roth C, Huang S, Hieter P, Lipka V, Wiermer M, Li X. 2014. An E4 ligase facilitates polyubiquitination of plant immune receptor resistance proteins in Arabidopsis. Plant Cell 26: 485-496. doi:10.1105/tpc.113 .119057

Huang Y, Cui Y, Hou X, Huang T. 2018. The AtMC4 regulates the stem cell homeostasis in Arabidopsis by catalyzing the cleavage of AtLal protein in response to environmental hazards. Plant Sci 266: 64-75. doi:10.1016/j .plantsci.2017.10.008

Johnson KCM, Xia S, Feng X, Li X. 2015. The chromatin remodeler SPLAYED negatively regulates SNC1-mediated immunity. Plant Cell Physiol 56: 1616-1623. doi:10 $.1093 / \mathrm{pcp} / \mathrm{pcv} 087$

Johnson KCM, Zhao J, Wu Z, Roth C, Lipka V, Wiermer M, Li X. 2017. The putative kinase substrate MUSE7 negatively impacts the accumulation of NLR proteins. Plant $J$ 89: 1174-1183. doi:10.1111/tpj.13454

Jones JDG, Dangl JL. 2006. The plant immune system. Nature 444: 323-329. doi:10.1038/nature05286

Jurkowski GI, Smith RK, Yu I, Ham JH, Sharma SB, Klessig DF, Fengler KA, Bent AF. 2004. Arabidopsis DND2, a second cyclic nucleotide-gated ion channel gene for which mutation causes the "defense, no death" phenotype. Mol Plant Microbe Interact 17: 511-520. doi:10.1094/ MPMI.2004.17.5.511

Kabbage M, Williams B, Dickman MB. 2013. Cell death control: the interplay of apoptosis and autophagy in the pathogenicity of Sclerotinia sclerotiorum. PLoS Pathog 9: e1003287. doi:10.1371/journal.ppat.1003287

Kemmerling B, Schwedt A, Rodriguez P, Mazzotta S, Frank M, Qamar SA, Mengiste T, Betsuyaku S, Parker JE, Müssig C, et al. 2007. The BRI1-associated kinase 1, BAK1, has a Brassinolide-independent role in plant cell-death control. Curr Biol 17: 1116-1122. doi:10.1016/j.cub.2007.05.046

Kim KS, Min JY, Dickman MB. 2008. Oxalic acid is an elicitor of plant programmed cell death during Sclerotinia sclerotiorum disease development. Mol Plant Microbe Interact 21: 605-612. doi:10.1094/MPMI-21-5-0605

Lapin D, Kovacova V, Sun X, Dongus JA, Bhandari DD, von Born P, Bautor J, Guarneri N, Rzemieniewski J, Stuttmann J, et al. 2019. A coevolved EDS1-SAG101-NRG1 module mediates cell death signaling by TIR-domain immune receptors. Plant Cell. doi:10.1105/tpc.19.00118

Lema Asqui S, Vercammen D, Serrano I, Valls M, Rivas S, Van Breusegem F, Conlon FL, Dangl JL, Coll NS. 2018. AtSERPIN1 is an inhibitor of the metacaspase AtMC1mediated cell death and autocatalytic processing in planta. New Phytol 218: 1156-1166. doi:10.1111/nph .14446

Li X, Clarke JD, Zhang Y, Dong X. 2001. Activation of an EDS1-mediated $R$-gene pathway in the sncl mutant leads to constitutive, NPR1-independent pathogen resistance. Mol Plant Microbe Interact 14: 1131-1139. doi:10.1094/ MPMI.2001.14.10.1131

Liu Y, Huang X, Li M, He P, Zhang Y. 2016a. Loss-of-function of Arabidopsis receptor-like kinase BIR1 activates cell death and defense responses mediated by BAK1 and SOBIR1. New Phytol 212: 637-645. doi:10.1111/nph.14072

Liu Z, Gao Y, Kim YM, Faris JD, Shelver WL, de Wit PJGM, Xu SS, Friesen TL. 2016b. SnTox1, a Parastagonospora nodorum necrotrophic effector, is a dual-function protein 
that facilitates infection while protecting from wheat-produced chitinases. New Phytol 211: 1052-1064. doi:10 $.1111 / \mathrm{nph} .13959$

Lolle S, Greeff C, Petersen K, Roux M, Jensen MK, Bressendorff S, Rodriguez E, Sømark K, Mundy J, Petersen M. 2017. Matching NLR immune receptors to autoimmunity in camta3 mutants using antimorphic NLR alleles. Cell Host Microbe 21: 518-529.e4. doi:10.1016/j.chom.2017 .03 .005

Lorang JM, Sweat TA, Wolpert TJ. 2007. Plant disease susceptibility conferred by a "resistance" gene. Proc Natl Acad Sci 104: 14861-14866. doi:10.1073/pnas.070257 2104

Lorang J, Kidarsa T, Bradford CS, Gilbert B, Curtis M, Tzeng SC, Maier CS, Wolpert TJ. 2012. Tricking the guard: exploiting plant defense for disease susceptibility. Science 338: 659-662. doi:10.1126/science.1226743

Menna A, Nguyen D, Guttman DS, Desveaux D. 2015. Elevated temperature differentially influences effector-triggered immunity outputs in Arabidopsis. Front Plant Sci 6: 1-7. doi:10.3389/fpls.2015.00995

Munch D, Rodriguez E, Bressendorff S, Park OK, Hofius D, Petersen M. 2014. Autophagy deficiency leads to accumulation of ubiquitinated proteins, ER stress, and cell death in Arabidopsis. Autophagy 10: 1579-1587. doi:10.4161/ auto. 29406

Negeri A, Wang GF, Benavente L, Kibiti CM, Chaikam V, Johal G, Balint-Kurti P. 2013. Characterization of temperature and light effects on the defense response phenotypes associated with the maize Rp1-D21 autoactive resistance gene. BMC Plant Biol 13: 106. doi:10.1186/1471-2229-13106

Niu D, Lin XL, Kong X, Qu GP, Cai B, Lee J, Jin JB. 2019. SIZ1-mediated SUMOylation of TPR1 suppresses plant immunity in Arabidopsis. Mol Plant 12: 215-228. doi:10 .1016/j.molp.2018.12.002

Paulus JK, Van der Hoorn RAL. 2019. Do proteolytic cascades exist in plants? J Exp Bot 70: 1997-2002. doi:10 $.1093 / \mathrm{jxb} / \mathrm{erz} 016$

Peters Haugrud AR, Zhang Z, Richards JK, Friesen TL, Faris JD. 2019. Genetics of variable disease expression conferred by inverse gene-for-gene interactions in the wheat-Parastagonospora nodorum pathosystem. Plant Physiol 180: 420-434. doi:10.1104/pp.19.00149

Phadnis N, Malik HS. 2014. Speciation via autoimmunity: a dangerous mix. Cell 159: 1247-1249. doi:10.1016/j.cell .2014 .11 .028

Qi T, Seong K, Thomazella DPT, Kim JR, Pham J, Seo E, Cho MJ, Schultink A, Staskawicz BJ. 2018. NRG1 functions downstream of EDS1 to regulate TIR-NLR-mediated plant immunity in Nicotiana benthamiana. Proc Natl Acad Sci 115: E10979-E10987. doi:10.1073/pnas.181 4856115

Raffaele S, Rivas S. 2013. Regulate and be regulated: integration of defense and other signals by the AtMYB30 transcription factor. Front Plant Sci 4: 98. doi:10.3389/fpls .2013 .00098

Rodriguez E, El Ghoul H, Mundy J, Petersen M. 2016. Making sense of plant autoimmunity and "negative regulators." FEBS J 283: 1385-1391. doi:10.1111/febs.13613
Roux F, Noël L, Rivas S, Roby D. 2014. ZRK atypical kinases: emerging signaling components of plant immunity. New Phytol 203: 713-716. doi:10.1111/nph.12841

Salguero-Linares J, Coll NS. 2019. Plant proteases in the control of the hypersensitive response. J Exp Bot 70: 2087-2095. doi:10.1093/jxb/erz030

Sheikh AH, Raghuram B, Eschen-Lippold L, Scheel D, Lee J, Sinha AK. 2014. Agroinfiltration by cytokinin-producing Agrobacterium sp. strain GV3101 primes defense responses in Nicotiana tabacum. Mol Plant Microbe Interact 27: 1175-1185. doi:10.1094/MPMI-04-14-0114-R

Shi G, Zhang Z, Friesen TL, Raats D, Fahima T, Brueggeman RS, Lu S, Trick HN, Liu Z, Chao W, et al. 2016. The hijacking of a receptor kinase-driven pathway by a wheat fungal pathogen leads to disease. Sci Adv 2: e1600822. doi:10.1126/sciadv.1600822

Shine MB, Xiao X, Kachroo P, Kachroo A. 2019. Signaling mechanisms underlying systemic acquired resistance to microbial pathogens. Plant Sci 279: 81-86. doi:10.1016/j .plantsci.2018.01.001

Stakman EC. 1915. Relation between Puccina graminis and plants highly resistant to its attack. J Agric Res 4: 193-199.

Świadek M, Proost S, Sieh D, Yu J, Todesco M, Jorzig C, Rodriguez Cubillos AE, Plötner B, Nikoloski Z, Chae E, et al. 2017. Novel allelic variants in ACD6 cause hybrid necrosis in local collection of Arabidopsis thaliana. New Phytol 213: 900-915. doi:10.1111/nph.14155

Tang D, Zhou JM. 2016. PEPRs spice up plant immunity. EMBO J 35: 4-5. doi:10.15252/embj.201593434

Tran DTN, Chung EH, Habring-Müller A, Demar M, Schwab R, Dangl JL, Weigel D, Chae E. 2017. Activation of a plant NLR complex through heteromeric association with an autoimmune risk variant of another NLR. Curr Biol 27: 1148-1160. doi:10.1016/j.cub.2017.03.018

Vaid N, Laitinen RAE. 2019. Diverse paths to hybrid incompatibility in Arabidopsis. Plant J 97: 199-213. doi:10 $.1111 /$ tpj.14061

Vanden BT, Linkermann A, Jouan-Lanhouet S, Walczak H, Vandenabeele P. 2014. Regulated necrosis: the expanding network of non-apoptotic cell death pathways. Nat Rev Mol Cell Biol 15: 135-147.

Wang GF, Balint-Kurti PJ. 2016. Maize homologs of CCoAOMT and HCT, two key enzymes in lignin biosynthesis, form complexes with the NLR Rp1 protein to modulate the defense response. Plant Physiol 171: 2166-2177. doi:10.1104/pp.16.00224

Wang G, Roux B, Feng F, Guy E, Li L, Li N, Zhang X, Lautier M, Jardinaud MF, Chabannes M, et al. 2015a. The decoy substrate of a pathogen effector and a pseudokinase specify pathogen-induced modified-self recognition and immunity in plants. Cell Host Microbe 18: 285-295. doi:10 $.1016 /$ j.chom.2015.08.004

Wang GF, Ji J, EI-Kasmi F, Dangl JL, Johal G, Balint-Kurti PJ. 2015b. Molecular and functional analyses of a maize autoactive NB-LRR protein identify precise structural requirements for activity. PLoS Pathog 11: e1004830. doi:10.1371/journal.ppat.1004830

Wang S, Wang S, Sun Q, Yang L, Zhu Y, Yuan Y, Hua J. 2017a. A role of cytokinin transporter in Arabidopsis immunity. Mol Plant Microbe Interact 30: 325-333. doi:10 .1094/MPMI-01-17-0011-R 
E. Pitsili et al.

Wang Z, Cui D, Liu J, Zhao J, Liu C, Xin W, Li Y, Liu N, Ren D, Tang D, et al. 2017b. Arabidopsis ZED1-related kinases mediate the temperature-sensitive intersection of immune response and growth homeostasis. New Phytol 215: 711-724. doi:10.1111/nph.14585

Wang J, Hu M, Wang J, Qi J, Han Z, Wang G, Qi Y, Wang HW, Zhou JM, Chai J. 2019a. Reconstitution and structure of a plant NLR resistosome conferring immunity. Science 364: eaav5870. doi:10.1126/science.aav5870

Wang J, Wang J, Hu M, Wu S, Qi J, Wang G, Han Z, Qi Y, Gao N, Wang HW, et al. 2019b. Ligand-triggered allosteric ADP release primes a plant NLR complex. Science 364: eaav5868. doi:10.1126/science.aav5868

Wang Z, Cui D, Liu C, Zhao J, Liu J, Liu N, Tang D, Hu Y. 2019c. TCP transcription factors interact with ZED1-related kinases as components of the temperature-regulated immunity. Plant Cell Environ 42: 2045-2056. doi:10 $.1111 /$ pce. 13515

Wiermer M, Feys BJ, Parker JE. 2005. Plant immunity: the EDS1 regulatory node. Curr Opin Plant Biol 8: 383-389. doi:10.1016/j.pbi.2005.05.010

Williams B, Kabbage M, Kim HJ, Britt R, Dickman MB. 2011. Tipping the balance: Sclerotinia sclerotiorum secreted oxalic acid suppresses host defenses by manipulating the host redox environment. PLoS Pathog 7: e1002107. doi:10.1371/journal.ppat.1002107

Wu CH, Belhaj K, Bozkurt TO, Kamoun S. 2016. Helper NLR proteins NRC2a/b and NRC3 but not NRC1 are required for Pto-mediated cell death and resistance in
Nicotiana benthamiana. New Phytol 209: 1344-1352. doi:10.1111/nph.13764

Wu CH, Abd-El-Haliem A, Bozkurt TO, Belhaj K, Terauchi R, Vossen JH, Kamoun S. 2017. NLR network mediates immunity to diverse plant pathogens. Proc Natl Acad Sci 114: 8113-8118. doi:10.1073/pnas.1702041114

Yu I, Parker J, Bent AF. 1998. Gene-for-gene disease resistance without the hypersensitive response in Arabidopsis dnd1 mutant. Proc Natl Acad Sci 95: 7819-7824. doi:10 $.1073 /$ pnas.95.13.7819

Zhang X, Dodds PN, Bernoux M. 2017. What do we know about NOD-like receptors in plant immunity? Annu Rev Phytopathol 55: 205-229. doi:10.1146/annurev-phyto080516-035250

Zhang N, Wang Z, Bao Z, Yang L, Wu D, Shu X, Hua J. 2018. MOS1 functions closely with TCP transcription factors to modulate immunity and cell cycle in Arabidopsis. Plant $J$ 93: 66-78. doi:10.1111/tpj.13757

Zhu Z, Xu F, Zhang Y, Cheng YT, Wiermer M, Li X, Zhang Y. 2010. Arabidopsis resistance protein SNC1 activates immune responses through association with a transcriptional corepressor. Proc Natl Acad Sci 107: 13960-13965. doi:10.1073/pnas.1002828107

Zhu W, Zaidem M, Van de Weyer AL, Gutaker RM, Chae E, Kim ST, Bemm F, Li L, Todesco M, Schwab R, et al. 2018. Modulation of $A C D 6$ dependent hyperimmunity by natural alleles of an Arabidopsis thaliana NLR resistance gene. PLoS Genet 14: e1007628. doi:10.1371/journal .pgen.1007628 


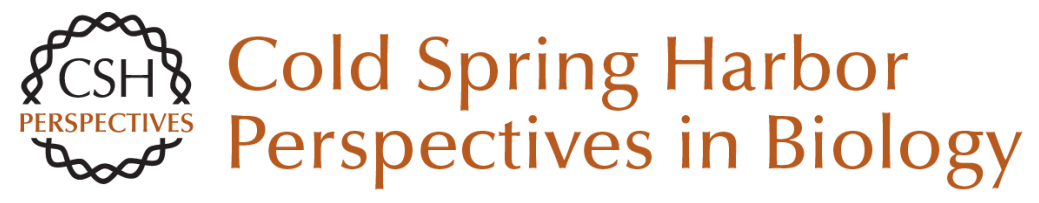

\section{Cell Death in Plant Immunity}

Eugenia Pitsili, Ujjal J. Phukan and Nuria S. Coll

Cold Spring Harb Perspect Biol 2020; doi: 10.1101/cshperspect.a036483 originally published online October 15, 2019

\section{Subject Collection Cell Survival and Cell Death}

Programmed Cell Death in the Evolutionary Race against Bacterial Virulence Factors

Carolyn A. Lacey and Edward A. Miao

The Evolutionary Origins of Programmed Cell

Death Signaling

Kay Hofmann

Regulation of Cell Death and Immunity by XIAP Philipp J. Jost and Domagoj Vucic

Dysregulation of Cell Death in Human Chronic Inflammation

Yue Li, Christoph Klein and Daniel Kotlarz

Cell Death in Plant Immunity

Eugenia Pitsili, Ujjal J. Phukan and Nuria S. Coll

\section{Recent Insights on Inflammasomes, Gasdermin}

Pores, and Pyroptosis

Nathalia M. de Vasconcelos and Mohamed Lamkanfi

Phagocyte Responses to Cell Death in Flies Andrew J. Davidson and Will Wood

Mechanism and Regulation of

Gasdermin-Mediated Cell Death

Shiyu Xia, Louis Robert Hollingsworth IV and Hao Wu
Cell Death and Neurodegeneration Benjamin J. Andreone, Martin Larhammar and Joseph W. Lewcock

Death Receptors and Their Ligands in Inflammatory Disease and Cancer Alessandro Annibaldi and Henning Walczak

The Killer Pseudokinase Mixed Lineage Kinase Domain-Like Protein (MLKL) James M. Murphy

Neutrophil Extracellular Traps in Host Defense Sabrina Sofia Burgener and Kate Schroder

Cell-Cycle Cross Talk with Caspases and Their Substrates

Patrick Connolly, Irmina Garcia-Carpio and Andreas Villunger

Cracking the Cell Death Code Carla V. Rothlin and Sourav Ghosh

BAX, BAK, and BOK: A Coming of Age for the BCL-2 Family Effector Proteins Tudor Moldoveanu and Peter E. Czabotar

Multitasking Kinase RIPK1 Regulates Cell Death and Inflammation Kim Newton

For additional articles in this collection, see http://cshperspectives.cshlp.org/cgi/collection/

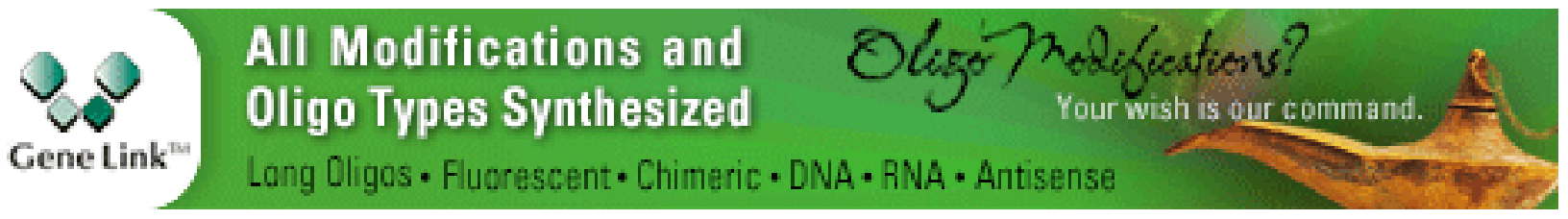


For additional articles in this collection, see http://cshperspectives.cshlp.org/cgi/collection/

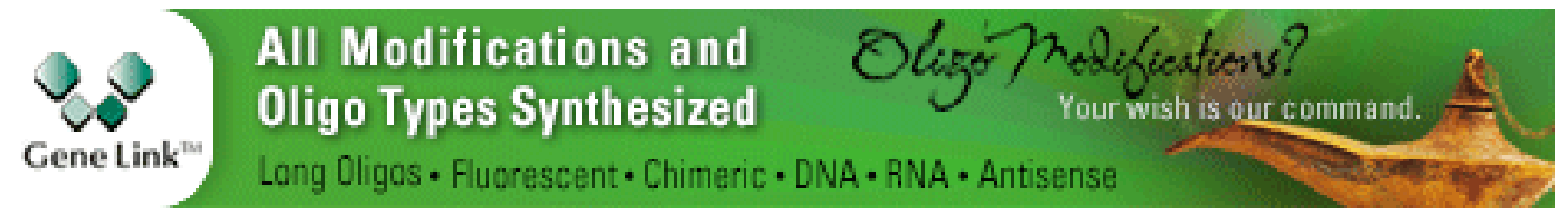

Copyright @ 2020 Cold Spring Harbor Laboratory Press; all rights reserved 